\title{
PSYCHOHYGIENIC ASPECTS OF TRAINING OF DISABLED ADOLESCENTS WITH PATHOLOGY OF THE VISION
}

\author{
Olga Sasina \\ Department of Hygiene and Ecology No 1 \\ Kharkiv National Medical University \\ 4 Nauky ave., Kharkiv, Ukraine, 61022, \\ ysatik83@ukr.net
}

\begin{abstract}
The objective of this article is to undertake a literature review to familiarize ourselves with the knowledge base; to summarize information about some psycho-hygienic aspects of teaching and visually impaired adolescents, including features of communication, learning environment, psycho-emotional stress in specialized educational institutions, as well as individual psychological characteristics of personality, emotional and volitional state of visually impaired and general patterns of physiological and psychological characteristics and health of adolescents with vision pathology. To examine the system of security measures in order to optimize the learning environment for the promotion of mental health of the studied contingent and the nature and impact of the learning environment on functional status and health of adolescents with vision pathology. To investigate the impact of current patterns of complex sanitary and regime-organizational factors of training on functional status and health of adolescents with vision pathology. A thorough literature review helps to lay the foundation for a study, and can inspires new research ideas. logical state.

Keywords: psychohygiene, the blind and visually impaired, psychoprophylaxis, education, visual disturbances, prenoso-
\end{abstract}

\section{Introduction}

According to the World Health Organization (WHO) today there are 40 million blind people in the world, 1.5 million of them - are children. As for Ukraine, 40 thousand people are suffering from true blindness and visually impaired people are five times more. And this number is increasing every year.

It is known that one of the most common causes of disability is blindness. Today, a variety of visual disturbances are extremely common worldwide. In recent years there was a tendency to growth of severe and disabling diseases that lead to loss of vision. Apart the causes, heredity, injury, complications at birth, infectious diseases, and common to all human diseases - environmental degradation, canned excess, etc. Important role played the tendency of civilization progress: the dominant role of vision, as a means of receiving and processing information. Each year, the flow of information increases, the visual system adapts to such loads much slower.

Throughout last few years the national programs to preserve and improve the health of the most vulnerable groups, namely children and adolescents with disabilities, namely "Children of Ukraine" (1996), the Concept of Health Development of Ukraine (2000), the Interdepartmental complex program "Health of the nation" (2002-2011) were adopted and actively implemented, and nationwide program "Health 2020: Ukrainian dimension" is currently developed.

\section{Aim of research}

The objective of this article is to summarize information about some psycho-hygienic aspects of teaching the blind and visually impaired adolescents.

\section{Psychohygienic aspects of learning for the blind and visually impaired}

One of the most urgent problems of today is the health of children and adolescents as well as reduction of the number of healthy children. Increasing proportion of children with chronic diseases and people with disabilities greatly reduces the potential for development of the country. In the last decade throughout the world, including Ukraine, a lot of attention is paid to the occurrence of child disability. The growth of the total number of children with disabilities and a high level of primary disability among the child population define the necessity of the state level measures for 
the correction of social policy for children with disabilities, the basic directions of that should be the prevention of disability, medical and pedagogical rehabilitation of children with disabilities, social adaptation, conducting primary preventive measures aimed at improving the stability of mental health, resilience of the psyche of children - defenseless against the influence of various environmental factors that would entail the prevention of severe secondary somatic and neuropsychiatric consequences already at the initial stage of their manifestations without severe socially significant violations [1].

According to the current classification blind persons are those, whose visual acuity is in the range from $0 \%$ to $0,04 \%$. Thus, contingent includes people fully devoid of vision (totally blind) and with residual vision (visual acuity from light perception to $0,04 \%$ ). Children with visual acuity from $0,05 \%$ to $0,2 \%$ are in the category of visually impaired, and may have to work with the help of sight under certain hygienic requirements [2].

One of the priorities of the existence and development of the prosperous state is to take care about getting high-quality and high-grade education by all the representatives of the younger generation, as stipulated in the Law of Ukraine "Higher Education", which is associated with creation of the necessary conditions for quality education of persons with disabilities including the blind and visually impaired. Totally blind children use touch and hearing to obtain educational information. Blind children with residual vision also obtain core training information through the sense of touch and hearing because such a profound defeat of vision use for a long time entails a negative impact on its further development. However, in the process of training and education residual vision is not ignored because it gives children more information about the environment. For a student with a visual disturbance it is important even before the start of classes to learn the movement and orientation in classrooms. It is necessary to maintain a constant placement of furniture and equipment in the classroom, and inform the visually impaired student about any changes in the room. Foreign methodologists prefer horseshoe seating arrangement of students when the teacher is in an open part of the "horseshoe" for easy access of all trainees to teacher. It is necessary to allow the student to sit where he better sees the board, but not separately from other students. In the room it is necessary to provide modifiable lighting conditions; because students may have different visual impairment, requirements to lighting are different for each student, in particular, adjustable lighting in different parts of the class is required to create different lighting conditions to meet the individual needs of students; local illumination, where it necessary; natural lighting and blinds to limit natural light and glare if necessary. The classroom should be with perfect acoustics, because the sound is very important for a blind student. It is also necessary to minimize the extraneous sounds. Special coating of the walls and floor softens the sound and improves the learning environment, and conversely uncovered floor can create an echo and distort intonation [3].

Visually impaired and disabled - is a special case, since $80 \%$ of the information people receive through the visual analyzer $[4,5]$. With a sharp decrease of vision, it interferes with the normal ability to self-care, movement in space, and also severely limits the possibility of learning and social interaction.

For a clearer perception of the problems of children with disabilities two groups of factors should be highlighted: the objective, depending on surrounding reality and subjective, depending directly on the person that can lead to mental health problems.

The objective factors include: a negative public perception of the disabled; low levels of social support, protection and assistance to persons with disabilities; not well-appointed accommodation and public areas for use by people with disabilities; low level of social status.

Subjective factors include: life position, consisting in passive and not an effort to feel like a full member of society; psychological self-awareness, underestimation of their capabilities, hidden personal potential; lack of life objectives, settings; rejection by society (isolation, aggression); the desire to learn, to work, to live [6].

It is known that all training programs must be aimed at solving the triune task: training and strengthening of health of students with regard to special schools for pupils with eye pathology, the additional challenges are facing them because they need to focus on both medical-social and psycho-hygiene aspects of training. 
For medical and social rehabilitation of students, adolescents with disabilities, with the pathology of vision it is necessary to develop a methodological program for the study of the functional state and health of adolescents, disabled due to ophthalmic pathology, which includes adequate, well proven currently researching methods, as well as the adaptation of special methods to study the functionality of people with ophthalmologic diseases.

According to many scientists, one of the most important factors influencing the functional state of the organism, its adaptation possibilities, level of health (both mental and physical), is a psychoemotional stress. Depending on the causes and conditions conducive to appearance of stress, the different stressful situations which early detection and elimination of risk factors of their occurrence can prevent the development of pathological processes are available [7].

Overcoming of borderline conditions helps the applying of adaptogenic measures. They are aimed at training the organism functions contained in the reactions of individual adaptation practices and maintaining constitutional evolutionarily conditioned defense mechanisms. In the period of adaptation and a compensatory stress of different severity adaptogenic activities should be preserving, correcting, and at the stage of adaptation "collapse" - with reducing character. Measures for the correction should be based on the objectification of evaluation of the organism functional state at the level of prenosological - premorbid state, as a result of mismatch between the organism capabilities and environmental requirements, which provokes predictors of pathological process [8].

One of the main tasks of the modern psychohygiene is providing mental health of individuals and population as a whole. Not less important task is psychohygiene - implementation of the measures of primary psychoprophylaxis, aimed at improving the mental health for resistance to the influence of various environmental hazards [7]. A subject of direct study of psychohygiene is presented by such common mental conditions such as personality accentuation, which under certain conditions can be transformed into the corresponding psychopathy - condition of the morbid character; various types of deviant behavior that bring personal and social danger; a wide range of borderline mental states that accompany the situation and risk periods and has neurotic character [8].

Prenosological states arise from dysfunction of the adaptive systems, which are currently intended to ensure stable functioning of the organism, and therefore the preclinical diagnosis is based on the definition of qualitative and quantitative indicators of the adaptation process, measured, and (or) calculated as a result of prophylactic examinations. The use of monitoring observation of the state health of students in special educational institutions for blind and visually impaired in the complex of hygienic diagnostic measures resolves the significantly extend of our views on the formation of prenosological states among students and accordingly propose a system of preventive measures for the correction of the functional state of the organism [8, 10-12].

Based on the direct and reverse incremental regression analysis, the statistical models that allow to predict the degree of probability of prenosological shifts in mental health, are developed, taking into account the characteristics of the living and social conditions, the mode of the day and training adaptation, characteristics of the psycho-physiological functions development of the body and the personality traits $[13,14]$.

\section{Result}

Introduction into the research activity of the borderline states involves the creation of well-structured system of diagnostic and corrective measures, enabling consistently meet the challenges of population health assessment, sanitary and preclinical diagnosing and hygienic correction of the functional state of the organism, whose ultimate goal is the preservation of the individual, population and public health [15].

However, it is necessary to emphasize that the current system of primary prevention is actually deprived of an extremely important element, which consists of objectification of evaluation of the functional state of the organism at prenosological state level in circumstances, where non-compliance, non-conformity of the organism capacity to environmental requirements and social conditions generate prerequisites for the formation of the pathological process $[16,17]$. 
Basic hygienic measures in special schools for children with pathology of the organ of vision are the prenosological hygienic diagnostics of the health state of students. It involves a detailed study of the whole complex of educational and domestic factors in connection with their targeted influence on child and adolescent organism. In addition, the development of methods for the detection and measurement of individual psychological characteristics of personality is needed [18]. The objective of these programs is to establish qualitative and quantitative characteristics of external influence. During experimental work on studying the modes of learning for the blind and visually impaired in specialized educational institutions one of actual tasks is to establish a thin line that separates the normal reaction to external environmental impacts from pathological manifestations.

Thus, the basis of our research is a natural experiment that allows to develop the set of effective measures of psychohygienic correction of the functional state of students, as well as to justify scientifically prognostic criteria for assessing social adaptation of the studied contingent, using modern adapted techniques. The search criteria for assessing the level of health are important to make timely and adequate organizational, medical and social measures for the correction of premorbid states [19, 20].

\section{Conclusions}

Thus, the analysis of foreign and native literature on sociocultural rehabilitation of people with special needs, gives grounds to say that:

1. The sphere of social protection and support is developing pretty rapidly in almost all countries of the world, but I can't mention the lack of study of the combined effect of educational and household activities on the functional state and the state of mental health of the adolescents with disabilities of organ vision, which belong to the "group of risk" of prenosological deviations in neuro-psychic sphere.

2. Today the task of studying and managing the development of child personality with special needs with a view to its fulfillment in the world of sighted people should be clearly set at the top of the issue.

3. For the organization of competent pedagogical work we must take into account not only the age, but also the individual characteristics of children, due to their personal psycho-emotional qualities, as well as differentiated features associated with the diagnosis of eye diseases, the degree of visual impairment and their health.

\section{References}

[1] Faal, H., Gilbert, C. (2007). Convincing Governments to act: VISION 2020 and the Millennium Development Goals. Community Eye Health Journal, 20 (64), 62-64.

[2] Zhaboedov, G. D., Skrypnyk, R. L., Baran, T. V. (2011). Ophthalmology. Kyiv, 412.

[3] Methodology of Teaching a Foreign Language to the Blind. Project "LISTEN \& TOUCH": A Basic English Course for the Visually Impaired. Socrates programme: Lingua-2.

[4] Zavyalova, A. V., Smirnova, V. M. (2009). Normal physiology. Moscow: "MEDpress-Inform”, 631 .

[5] Rosenberg, E. A., Sperazza, L. C. (2008). The visually impaired patient. Am Fam Physician, 77 (10), 1431-1436.

[6] McLeod, B. D., Southam-Gerow, M. A., Tully, C. B., Rodríguez, A., Smith, M. M. (2013). Making a Case for Treatment Integrity as a Psychosocial Treatment Quality Indicator for Youth Mental Health Care. Clinical Psychology: Science and Practice, 20 (1), 14-32. doi: 10.1111/cpsp.12020

[7] Biryukov, N. A. (2006). Healthcare technologies in educational institutions. Hygiene and sanitation, 1, 76-77.

[8] Lesovoy, V. N., Kapustnik, V. A., Korobchanskiy, V. A. (2013). Medicine of borderline conditions: theory and practice of prenosological diagnostics. Scientific journal of Health Ministry of Ukraine, 2 (3), 49.

[9] Psychohygiene: Ukrainian-Russian Dictionary (2008). Kharkiv: Contrast, 192. 
[10] Korobchanskiy, V. A. (2005). Hygienic psychodiagnostics of prenosological states in adolescence and early adulthood. Guide for doctoral students, graduate students, applicants and physicians. Kharkiv: Contrast, 4-5.

[11] Korobchanskiy, V. A., Mikheev, V. V., Vasilchenko, I. O. (2007). Psychohygienic problems of prenosological diagnostics of adolescent's mental health problems. Bulletin of Hygiene and Epidemiology, 11 (2), 232-233.

[12] Korobchanskiy, V. A., Vytrischak, S. V. (2015). Hygienic prenosological psychodiagnostic: methodological basis and practical perspectives. Environment and Health, 4, 9-14.

[13] Bardov, V. G., Serheta, I. V. (2000). Hygienic basis of prediction the health of children and adolescents. Problems of medicine, 1-2, 41-46.

[14] Serheta, I. V., Bratkova, O. Y. (2007). Hygienic aspects of diagnostics and correction of changes in the emotional sphere of 15-17 years old adolescents. Bulletin of Hygiene and Epidemiology, 2, 234-237.

[15] Korobchanskiy, V. O., Reznichenko, O. G., Veremiyenko, O. V. (2015). Hygienic assessment and optimization of the functional state of students in higher education institutions through the introduction of the medicine of extreme conditions principles. Experimental and clinical medicine, 3 (68), 157.

[16] Serheta, I. V. (2013). Prenosological changes in mental state, modern psychohygienic approaches to interpretation, diagnosis and evaluation. Scientific Journal of Health of Ukraine, 3 (4), 36.

[17] Cone, J. D. (1997). Issues in functional analysis in behavioral assessment. Behaviour Research and Therapy, 35 (3), 259-275. doi: 10.1016/s0005-7967(96)00101-5

[18] Korobchanskiy, V. A. (2007). Psychohygiene: our understanding in 2007. Medical practice, $1,108-115$.

[19] Serheta, I. V. (1995). Hygienic aspects of rehabilitation of teenagers the marginal psychological disorders. Medical Rehabilitation, 4, 19-22.

[20] Korobchanskiy, V. A., Lantukh, A. P., Vitrischak, S. V., Brodetsky, Y. U. (2008). The phenomenon of marginality in the modern Ukrainian society: methodological, sociological and psycho-hygienic aspects. Lugansk: LugGMU, 312. 